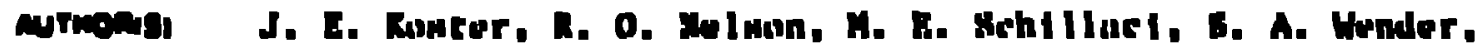

D. Mro, F. P. Brady, J. Mnerro, D. Brofehork, M. Blann,

P. Anchonv, V. B. Brown, I., llanuon, B. Puhl, T. G. Sanketer,

H. Sifenseker, and J, A, Pinntom

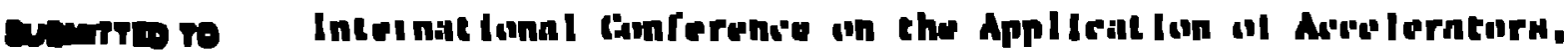

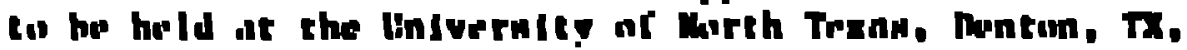

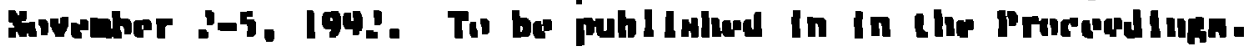

\title{
TimTAMM
}

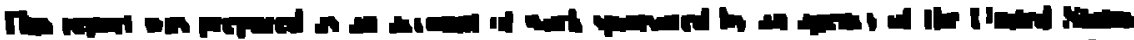

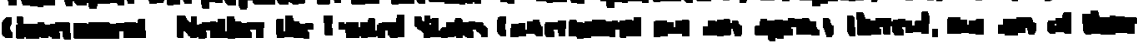

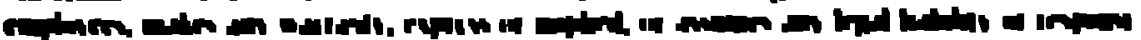

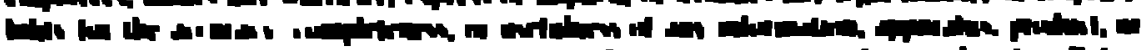

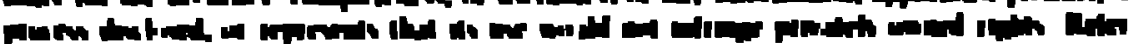

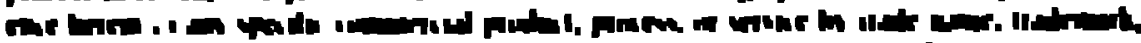

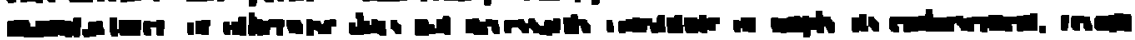

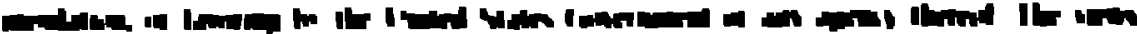

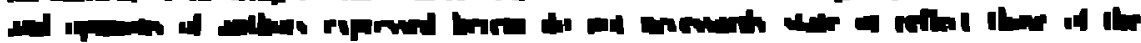

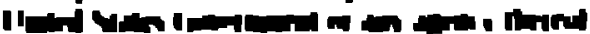

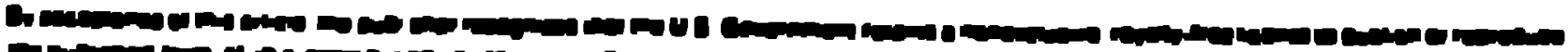
a
}

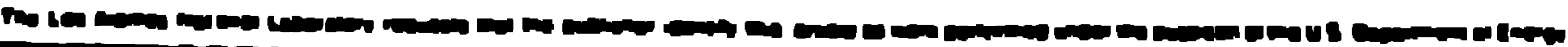

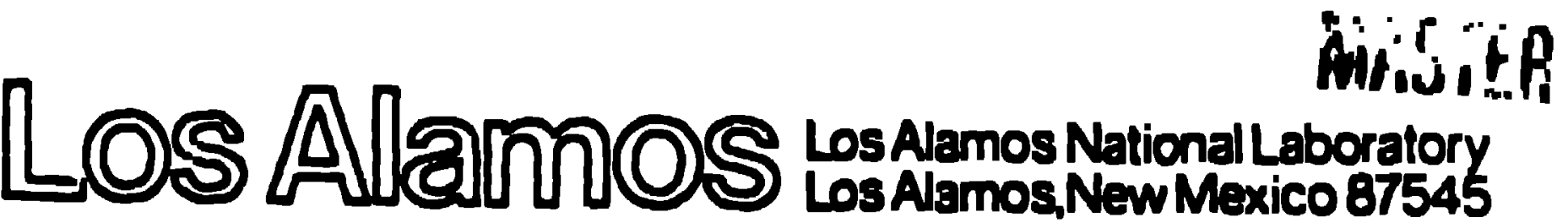




\title{
NEUTIUN-PROTUN BREMSSTRAHLUNG EXPEIIAN'TS
}

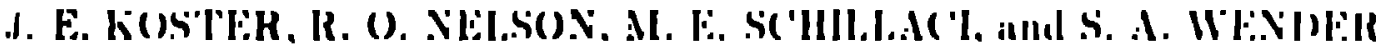

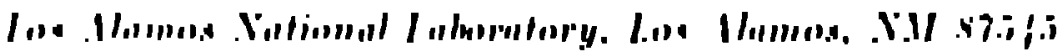

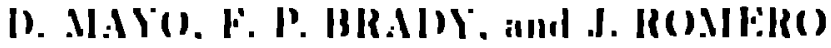

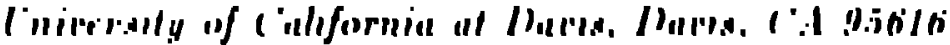

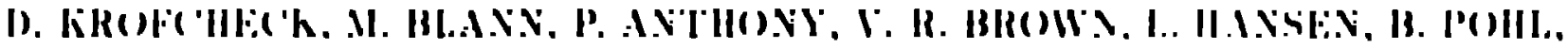

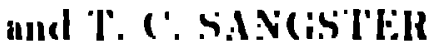

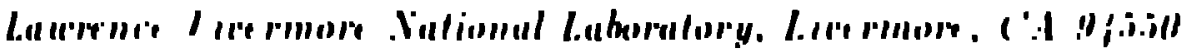

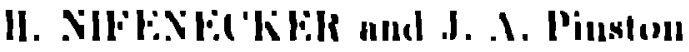

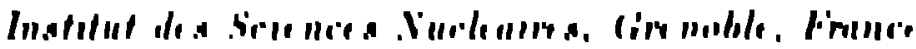

It is wroll known that rharged particles omit hre'msst rahlung radiation when they

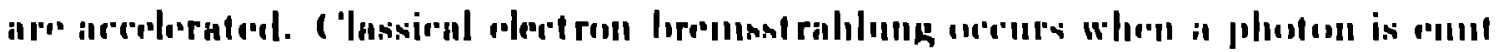

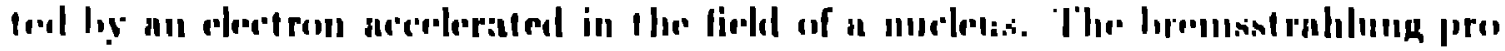

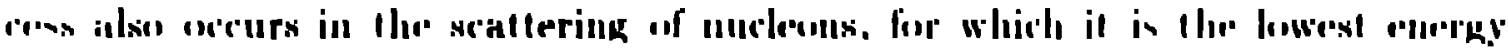

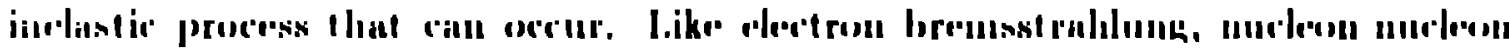

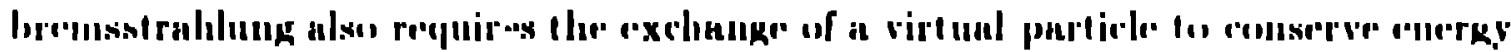

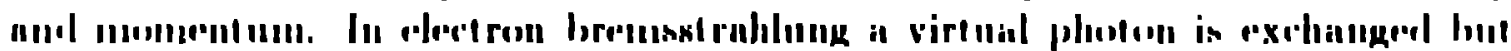

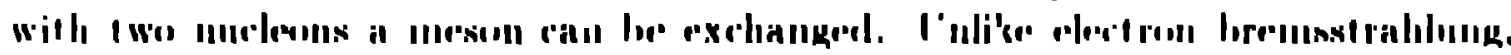

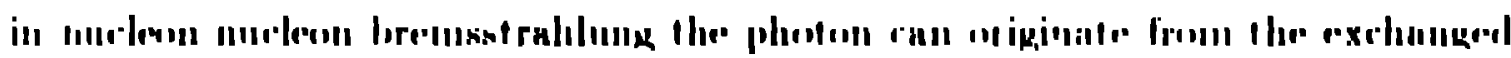

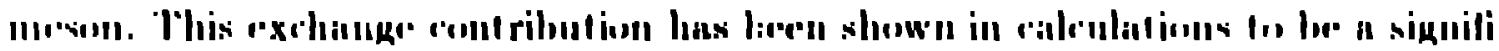

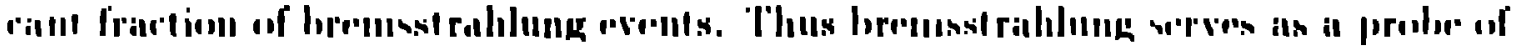

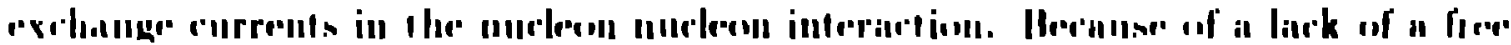

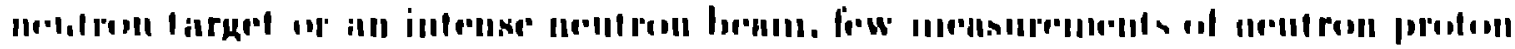

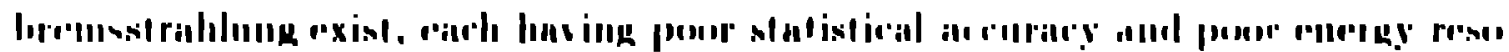

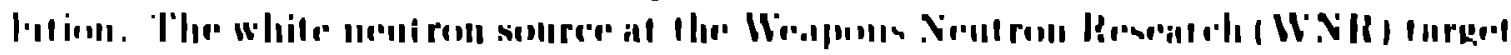

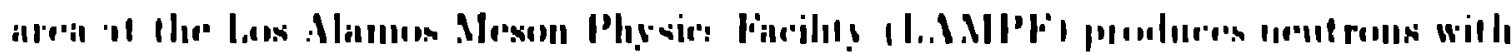

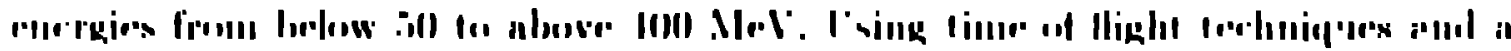

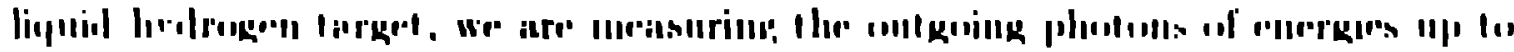

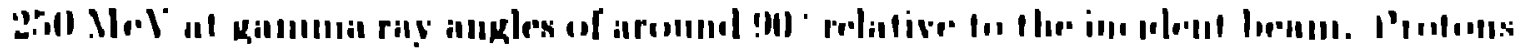

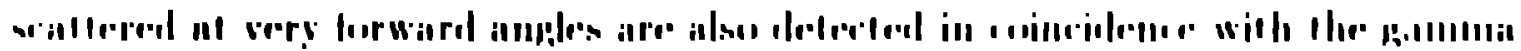
$1.11 \cdot$.

\section{IN'III(I)III "IIIN}

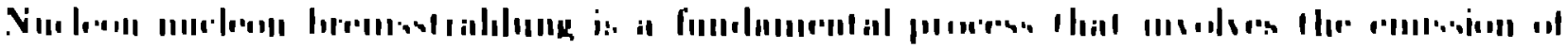

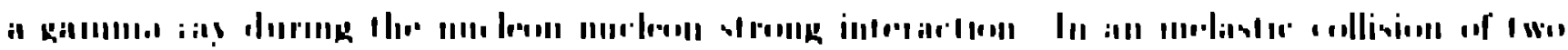

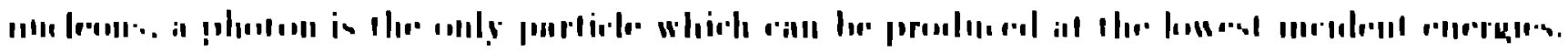

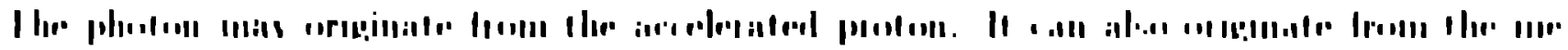

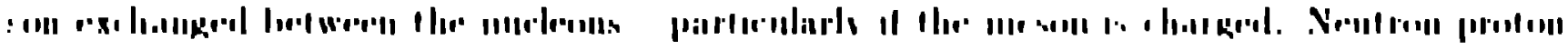

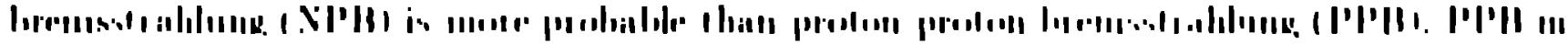

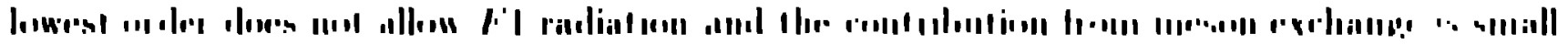

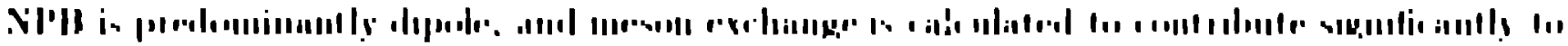




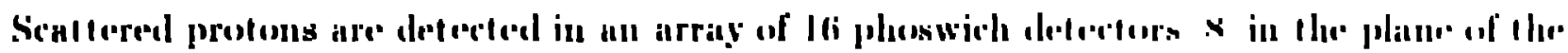

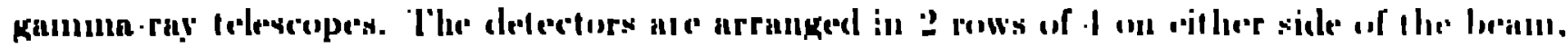

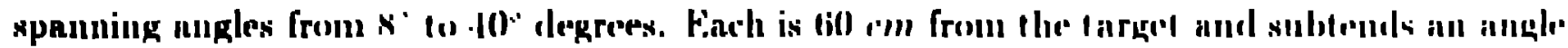

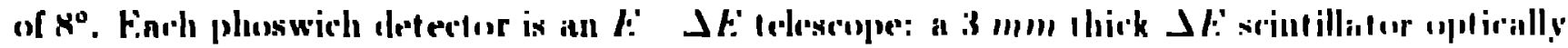

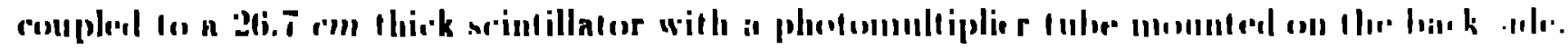

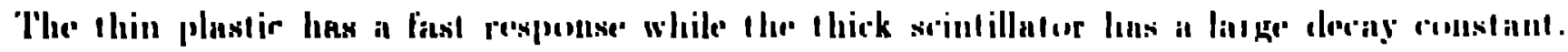

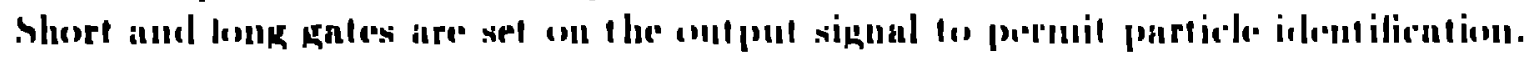

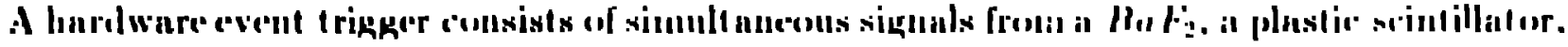

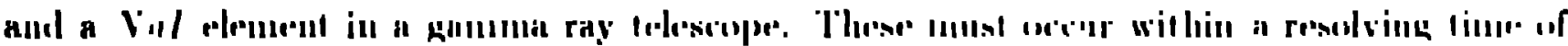

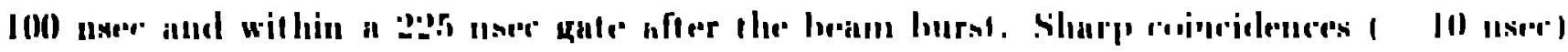

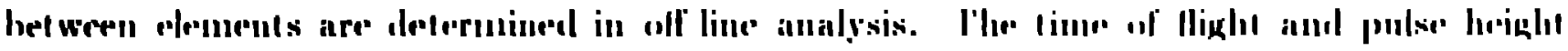

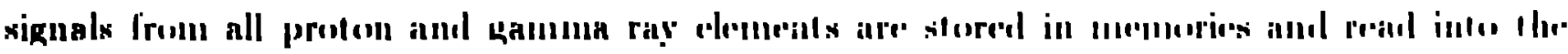

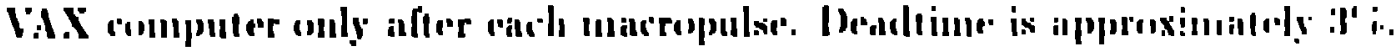

\section{RESULTS}

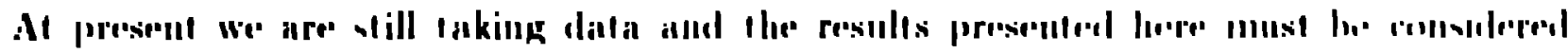

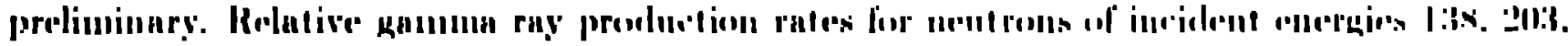

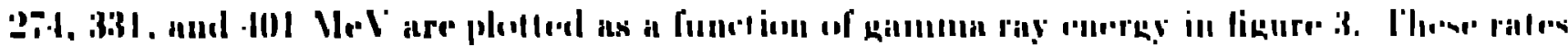

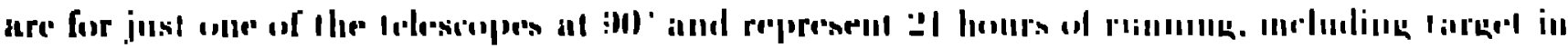

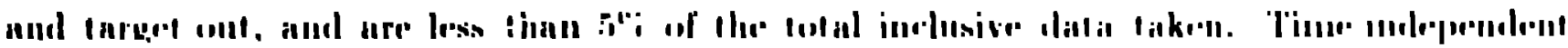

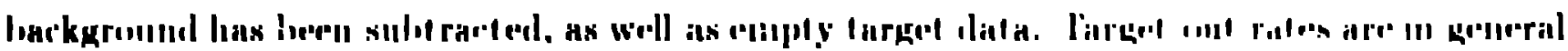

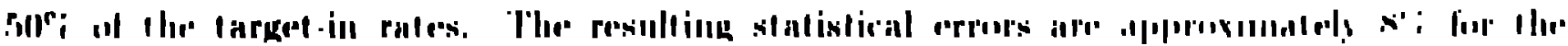

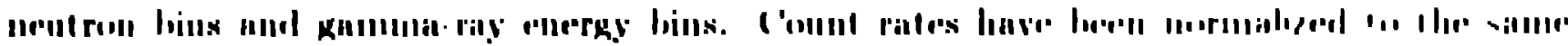

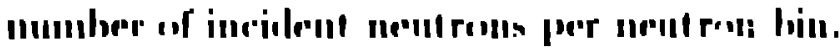

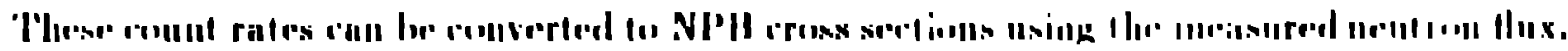

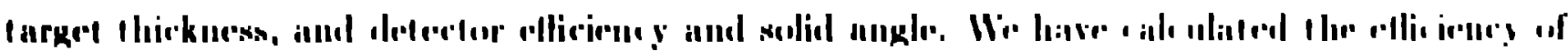

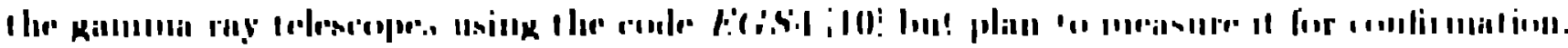

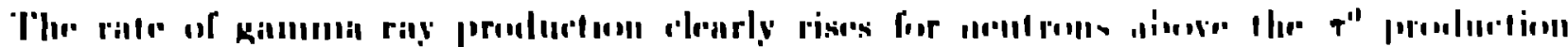

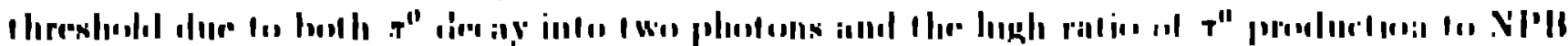
arousn serelienll.

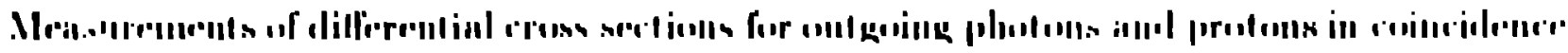

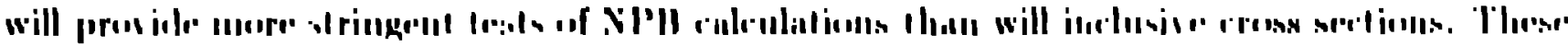

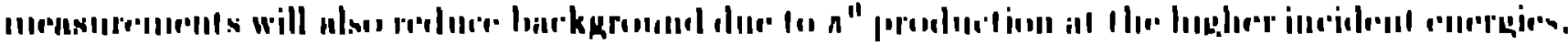

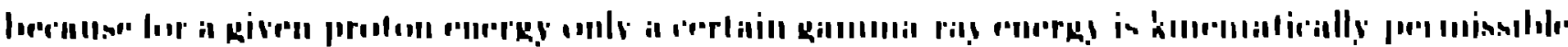

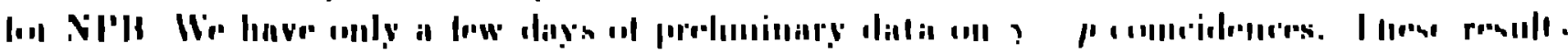

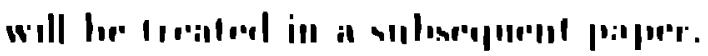

\section{A('KN()WLGI)(ikiMIr:N'l'}

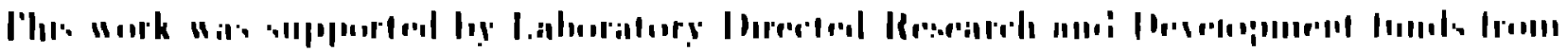

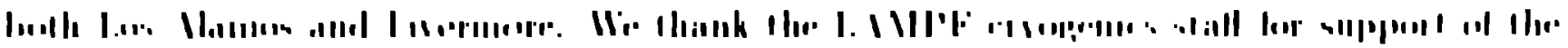

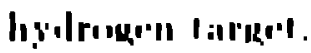

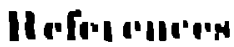

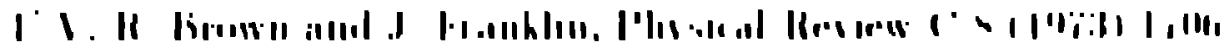




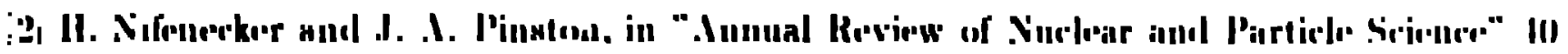
( L!OS) I I:3.

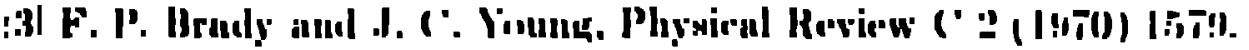

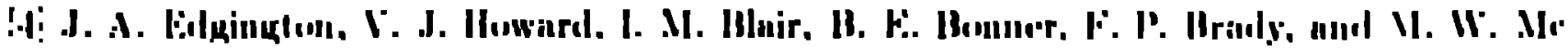

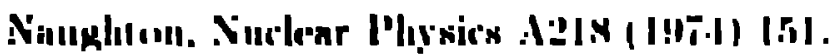

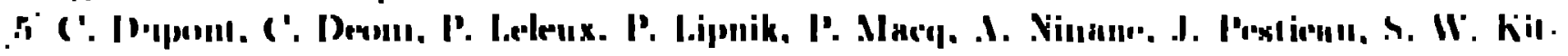

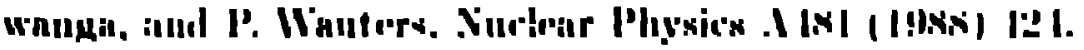

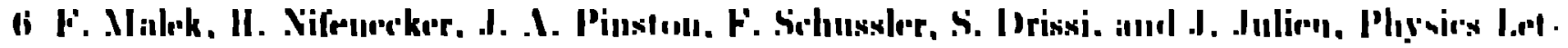

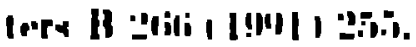

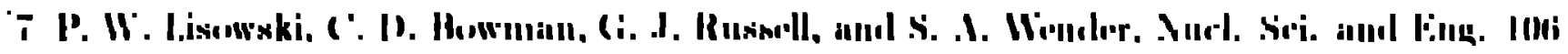
( I!)!)|| :(1).

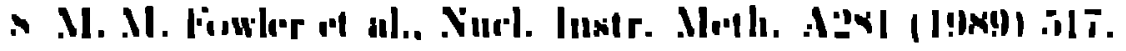

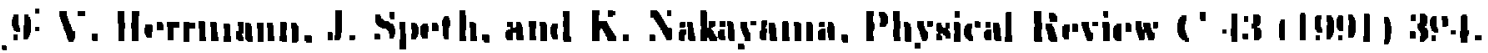

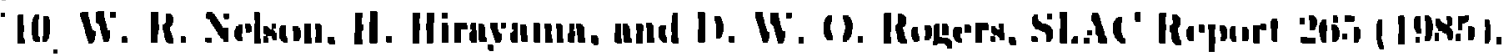




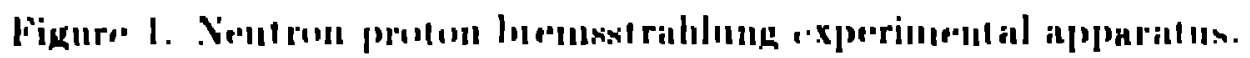

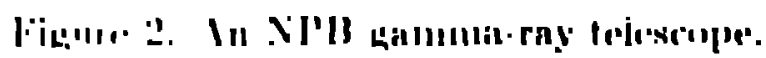

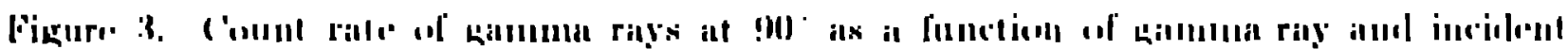

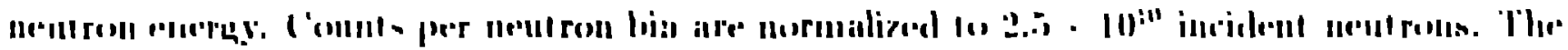

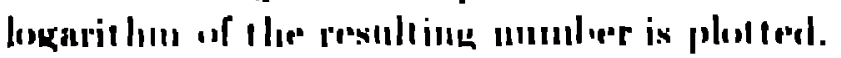




\section{NPB Experimental Apparatus}

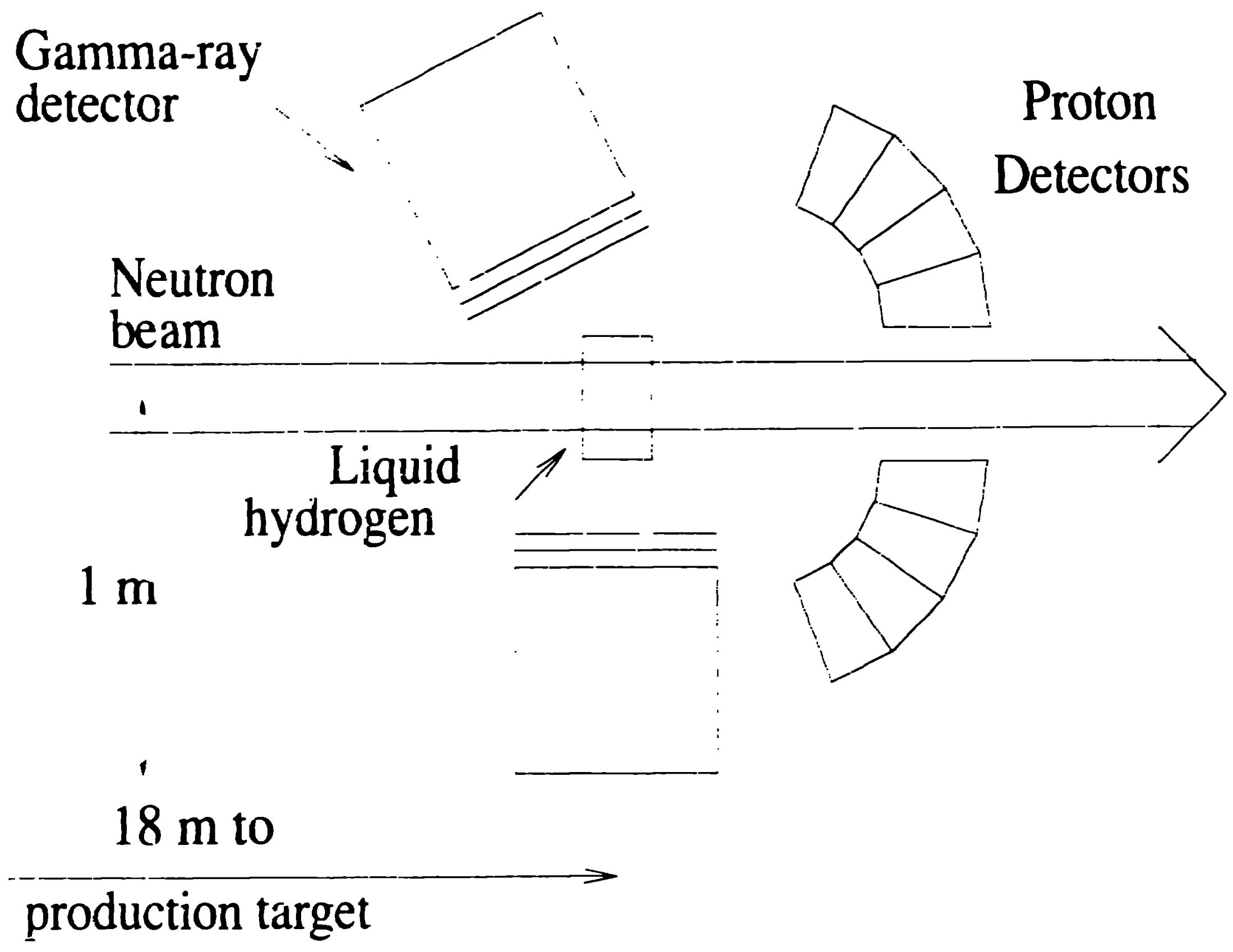




\section{NEUTRO \-PRO'ON BREMSSTRAHLUNC DETECTOR}

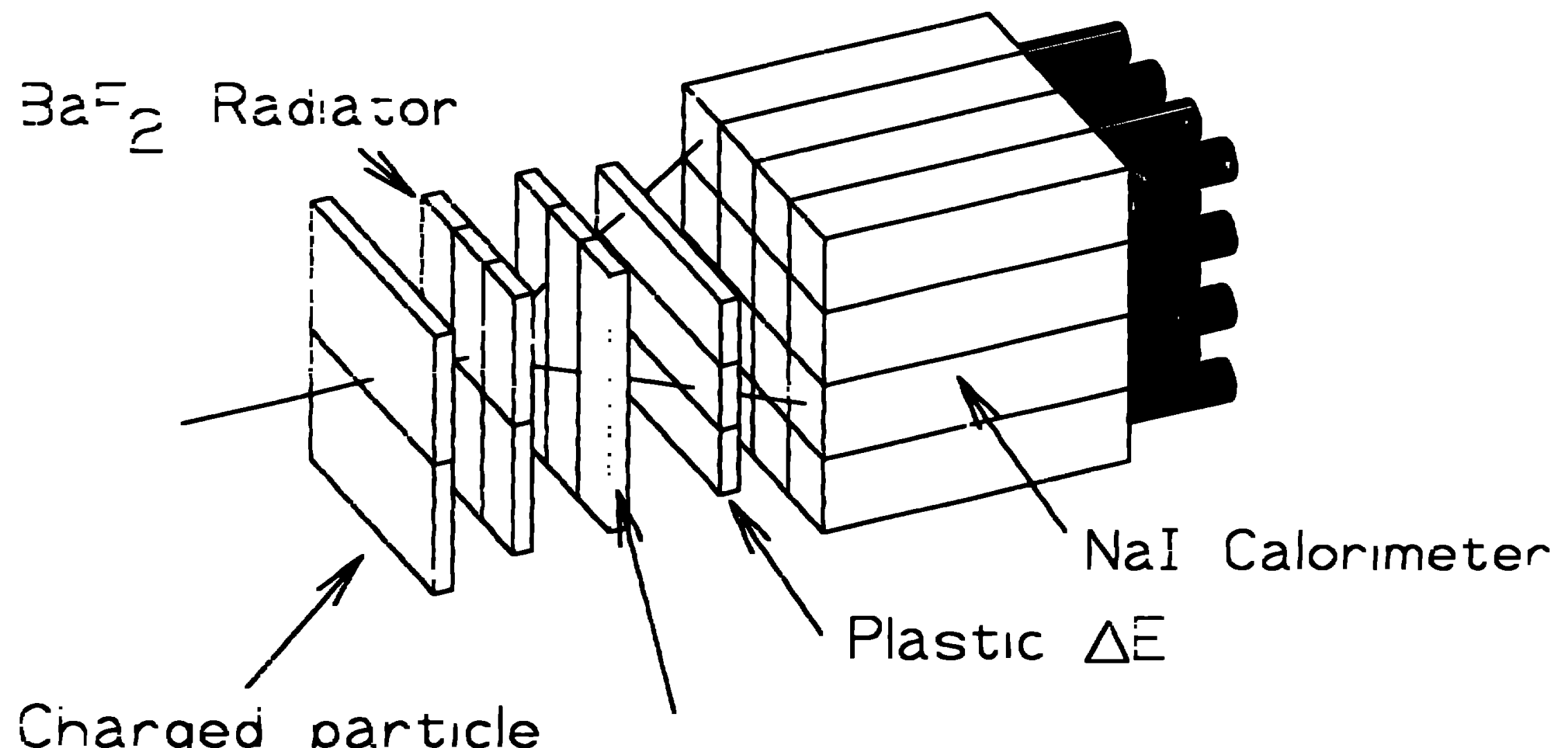

Cerenkov Veto 
Gamma ray production at 90 degrees

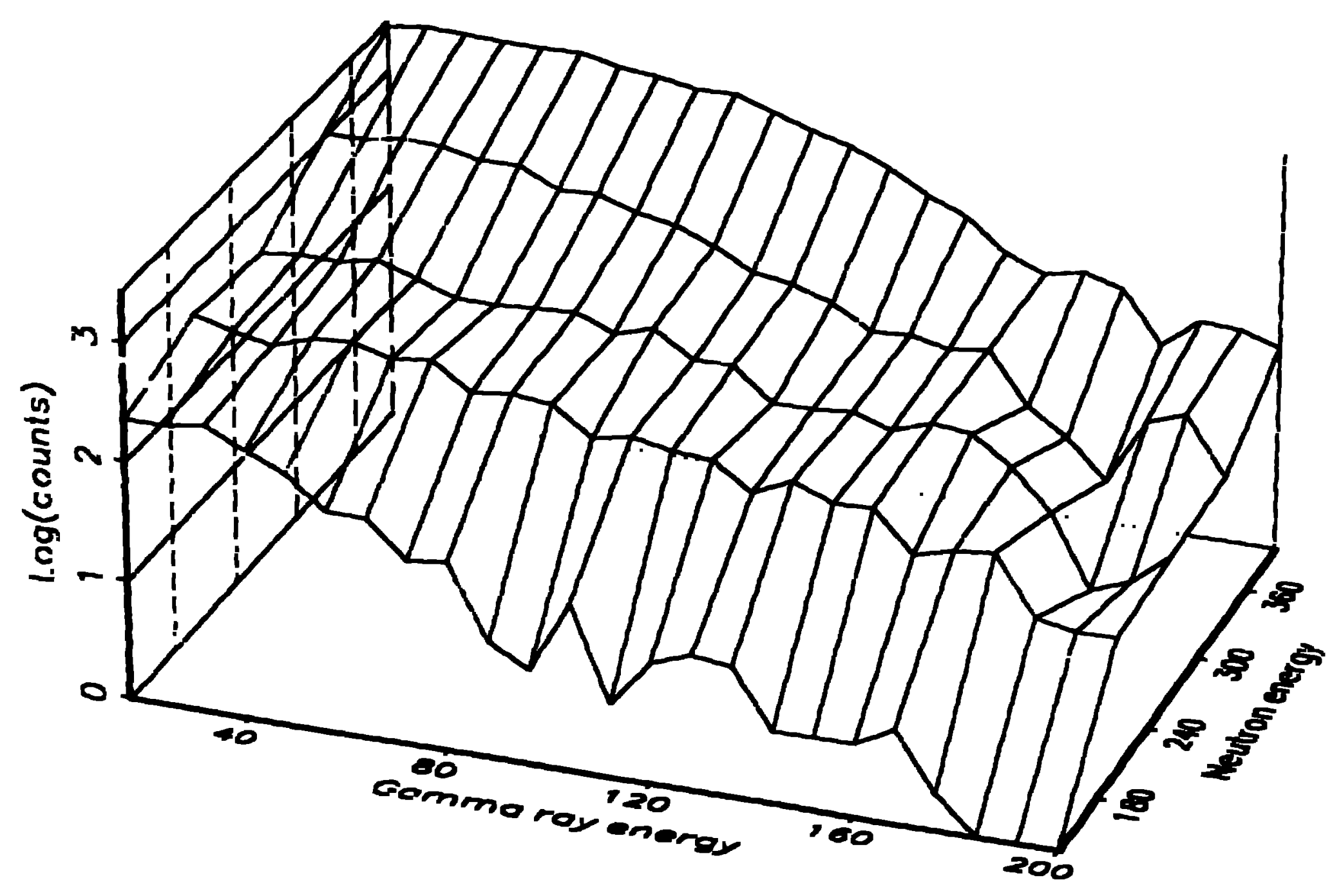

